\title{
Planar arrangement of eukaryotic cells in merged hydrogels combines the advantages of 3-D and 2-D cultures
}

\author{
Alexander A. Gordeev, Helena V. Chetverina, and Alexander B. Chetverin \\ Institute of Protein Research of the Russian Academy of Sciences, Pushchino, Moscow Region, Russia
}

BioTechniques 52:325-331 (May 2012) doi 10.2144/000113861

Keywords: suspension cells; adherent cells; population studies; cell immobilization; high-throughput screening; cell lines; cell cloning

Supplementary material for this article is available at www.BioTechniques.com/article/113861

We report an unordered 2-D array of eukaryotic cells completely embedded in a 3-D matrix. Every cell is located at the same distance from the gel surface, which ensures uniformity of growth conditions and ease of observation characteristic of a 2-D culture. Each cell is firmly immobilized, and each has a unique address in the array. The cells can be rapidly screened, individually monitored during extended time periods, and cultured with the formation of spheroid microcolonies characteristic of a 3-D culture. Individual microcolonies can be extracted from the gel and further propagated, thus enabling isolation of pure cell clones from rather dense cell populations and rapid drug-free generation of stable cell lines.

There is ample evidence that $3-\mathrm{D}$ cell cultures better mimic the in vivo conditions of a multicellular organism than do 2-D cultures, in which cells adhere to glass or plastic surfaces (1-4). Often, the responses of cells in a 2-D culture to various cues are quite dissimilar from those of the cells in vivo or in a $3-\mathrm{D}$ culture $(5-8)$. This is partly because the physiology of a cell is determined, in addition to the genome, by the microenvironment, including mechanical properties of the extracellular matrix (ECM) and physical and chemical anisotropies $(2,9-11)$, which are quite different in $3-\mathrm{D}$ and 2-D cultures $(7,12,13)$. Therefore, 3-D cultures are preferable over 2-D for the use in a number of fields, such as studies on stem cell differentiation, tissue morphogenesis, cancer biology, cell-virus interactions, and cell-based drug screening and toxicology assays $(1,14,15)$.

Still, 2-D cultures cultures have the advantage of presenting every cell in the same plane. This ensures that all the cells are cultured under identical conditions, including gas exchange, nutrition supply and waste removal, and permits the cells to be easily monitored, screened, and collected for further use. On the contrary, in a 3-D culture, cells located at different distances from the surface encounter different physiological conditions $(3,8)$. A variety of sophisticated and expensive systems have been developed to minimize such chemical gradients (3). Another problem is the difficulty of using conventional microscopes for monitoring cells immersed at different depths in a highly scattering medium (7). Both the problems were partially overcome by "on-top" cultures, in which cells are cultured in a liquid medium while being attached to a surface of a gel, while mimicking to some extent the conditions of a 3-D culture $(16,17)$. However, in such a format, cells and their progeny are not securely immobilized and may occasionally migrate into the surrounding solution. Also, before they become attached to the gel surface, cells tend to aggregate with one another and may unevenly spread over the gel surface (17).

Here we report unordered 2-D arrays of eukaryotic cells that combine the advantages of the microenvironment of a 3-D culture with the uniformity of conditions and ease of observation characteristic of a 2-D culture. This planar 3-D culture may be of use in a number of research and applied fields requiring observation, manipulation, and proliferation of a large number of individual eukaryotic cells under strictly controlled conditions.

\section{Materials and methods}

Adherent cells-HeLa (CCL-2; ATCC, Manassas, VA, USA), HEK-293 (CRL-1573), H1299 (CRL-5803), and
SC-1 (CRL-1404)-were grown to $90 \%-100 \%$ confluence in $25 \mathrm{~cm}^{2}$ flasks and dispersed according to the ATCC protocol (www.lgcstandards-atcc.org) followed by the addition of $10 \mathrm{~mL}$ Dulbecco's modified Eagle's medium (DMEM) supplemented with 10\% FBS (PAA Laboratories, Pasching, Austria), 4 $\mathrm{mM}$ glutamine, $50 \mathrm{U} / \mathrm{mL}$ penicillin, and $50 \mu \mathrm{g} / \mathrm{mL}$ streptomycin. Suspension cells DT40 (CRL-2111) were grown in DMEM supplemented with $8 \%$ FBS, $2 \%$ chicken serum (cat. no. C5405; Sigma-Aldrich, St. Louis, MO, USA), 2 mM glutamine, $50 \mu \mathrm{M} 2$-mercaptoethanol, $50 \mathrm{U} / \mathrm{mL}$ penicillin, and $50 \mu \mathrm{g} / \mathrm{mL}$ streptomycin until the density of $10^{6} \mathrm{cell} / \mathrm{mL}$, whereas cells K-562 (CCL-243) were grown in RPMI-1640 medium supplemented with $10 \%$ FBS, $4 \mathrm{mM}$ glutamine, $50 \mathrm{U} / \mathrm{mL}$ penicillin, and $50 \mu \mathrm{g} / \mathrm{mL}$ streptomycin until the density of $0.5 \times 10^{6}$ cells $/ \mathrm{mL}$.

For transfecting HEK-293 cells, 0.3 $\mu \mathrm{g}$ GFP-encoding plasmid pEGFP-C3 (Clontech Laboratories, Mountain View, CA, USA) and $1 \mu \mathrm{L}$ Unifectin-56 (Unifect Group, Moscow, Russia) were mixed with $225 \mu \mathrm{L}$ serum-free DMEM, incubated for $20 \mathrm{~min}$ at $22^{\circ} \mathrm{C}$, and added to a well of a 12-well plate containing 1-day-old $50 \%-70 \%$ confluent cell layer under 0.9 $\mathrm{mL}$ of the complete growth medium, and the cells were grown for one more day before use. 
A

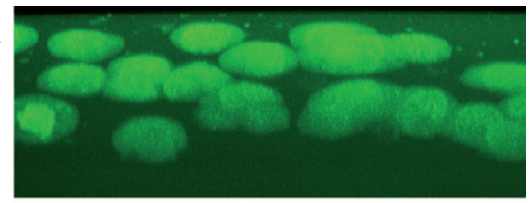

B

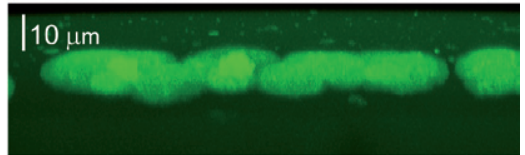

C

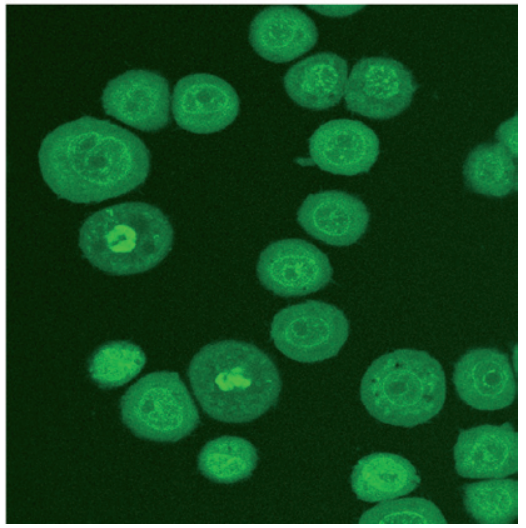

Figure 1. HeLa cells in merged gels. Cells suspended in molten $0.5 \%$ agarose were poured into a well made in a microscopic slide, the well bottom being covered with a dry PAA gel, followed by cooling the slide on ice. Shown are confocal microscope images of fluorescently stained cells. (A) Side view of a cell layer formed without centrifugation. (B) Side view of a cell layer formed upon spinning the slide at 100× $\mathrm{g}$ for $1 \mathrm{~min}$ at $25^{\circ} \mathrm{C}$ before transferring it to $4^{\circ} \mathrm{C}$. (C) Median optical section of the layer shown in panel $\mathrm{B}$.

Polyacrylamide (PAA) gels were cast in 14-mm-diameter, 0.4-mm-deep wells, then washed and dried as reported (18). Merged gels were prepared as follows. Cells were pelleted in a centrifuge for $5 \mathrm{~min}$ at $200 \times g$ (or $300 \times g$ for DT40), resuspended in Dulbecco's phosphate-buffered solution (DPBS; $8 \mathrm{mMNa}_{2} \mathrm{HPO}_{4} / 1.5 \mathrm{mM} \mathrm{KH}_{2} \mathrm{PO}_{4}$, $\mathrm{pH} 7.5,138 \mathrm{mM} \mathrm{NaCl}^{4}, 2.7 \mathrm{mM} \mathrm{KCl}, 0.9$ $\mathrm{mM} \mathrm{CaCl}, 0.5 \mathrm{mM} \mathrm{MgCl}_{2}$ ) to the desired concentration, and incubated for $2 \mathrm{~min}$ at $30^{\circ} \mathrm{C}$. The cell suspension was mixed $(1: 1$, v/v) with a cooled to $30^{\circ} \mathrm{C}$ molten $1 \%$ agarose (Type IX, Ultra-low Gelling Temperature, cat. no. A5030; Sigma-Adrich) in DPBS, and $70 \mu \mathrm{L}$ mixture were poured into a well containing dry PAA gel film attached to its bottom, with simultaneous sliding a coverslip over the well. In case of inverted merged gels, the PAA gel was attached to the coverslip. Where indicated, the slide was spun for $1 \mathrm{~min}$ at $100 \times g, 25^{\circ} \mathrm{C}$ in centrifuge 5804R (Eppendorf, Hamburg, Germany), by placing the slide with the agarose layer facing up on the tube adapter of a bucket rotor (cat. no. A-4-44; Eppendorf). The agarose was then solidified at $4^{\circ} \mathrm{C}$ for $20 \mathrm{~min}$.

Cells were inspected using wide-field inverted microscope DM IRE 2 with

A

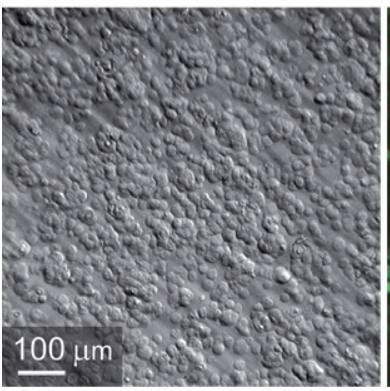

B

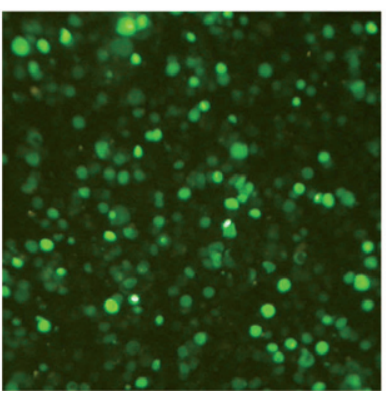

C

Figure 2. Screening a population of cells for those producing GFP. (A) Bright field microscope image of a monolayer of HEK-293 cells transfected with a GFP-encoding plasmid and embedded in merged gels at a density of $1300 / \mathrm{mm}^{2}$. (B) The same field in a GFP fluorescence mode. (C) A field showing one of eight GFP-containing cells found among $2 \times 10^{5}$ cells from a monolayer prepared using a 1:10,000 dilution of the population shown in panel B with nontransfected cells.

mechanical stage, integrated into the AS TP system (Leica Microsystems GmbH, Wetzlar, Germany), in either a bright field mode using the Leica modulation contrast or in a GFP fluorescent mode using the I3 filter cube (excitation filter BP 450/490, dichromatic mirror 510 , suppression filter LP 515). Images were obtained using either Coolpix 4500 photo camera (Nikon Russia, Moscow, Russia) or Cascade II 512 video camera (Photometrics, Tucson, AZ, USA). Optical sections and side views of fluorescing cells and microcolonies in the GFP fluorescent mode were obtained using confocal microscope TCS SPE DM2500 and LAS AF Version 2.1.0 build 4316 software (Leica). Where indicated, non-GFP-producing cells were stained with a broad range fluorescent ink by spotting the side of the coverslip facing the gel with a $\mathrm{CD} / \mathrm{DVD} / \mathrm{BD}$ marker (LINER 2616; Centropen, Prague, Czech Republic; www.centropen.cz/productcatalogue/for-the-office/12-3-cddvdbdmarkers/38-cddvdbd-liner-2616).

Microcolonies were grown in inverted merged gels whose agarose layer contained an appropriate complete growth medium with or without $0.5 \mathrm{mg} / \mathrm{mL}$ bovine skin collagen (cat. no. C4243; Sigma-Aldrich). The gels were incubated upside down in a $40-\mathrm{mm}$ Petri dish at $37^{\circ} \mathrm{C}$ and $5 \% \mathrm{CO}_{2}$ under $3 \mathrm{~mL}$ growth medium. Microcolonies were extracted by sucking with a disposable $70-\mu \mathrm{m}$ inner diameter glass micropipet made from a borosilicate glass capillary tubing (cat. no. BF100-5010; Sutter Instrument Company, Novato, CA, USA) using P-97 MicropipetPuller (Sutter Instrument). The micropipet was operated with the CellTram Air microinjector (Eppendorf Austria GmbH, Vienna, Austria) mounted on the TransferMan NK 2 micromanipulator (Eppendorf) integrated into the Leica AS TP system.

\section{Results and discussion}

We prepared 2-D cell arrays using merged PAA/agarose gels (18-19). To this end, a suspension of cells in molten low-gelling temperature agarose was poured in a shallow well made in a microscope slide having a previously cast and dried polyacrylamide gel covalently attached. When the PAA gel swells by absorbing the liquid, it displaces cells toward the coverslip. Upon formation, the agarose gel becomes partly merged with the PAA gel and immobilizes cells concentrated on the PAA gel surface. Sometimes, especially for the experiments on cell growth and cloning, we used inverted merged gels. In this case, the dry PAA matrix was covalently attached to a glass slip covering a well filled with molten agarose containing cells.

To become immobilized, cells must be submerged in the agarose gel at some depth; hence, the agarose must harden before it is completely sucked up by the PAA matrix. However, in this case, cells are not layered into a monolayer; rather, they populate the entire space above the PAA surface (Figure 1A). We found that a nearly perfect monolayer can be generated by briefly spinning the slide in a centrifuge while the agarose is still liquid; this forces all the cells to sediment on the swelling PAA bed. When the PAA gel was made of $7 \%$ acrylamide and $0.07 \%$ bisacrylamide, the cells were submerged at a depth of $10 \mu \mathrm{m}$ (Figure 1B). Decreasing the acrylamide concentration to $4 \%$ and increasing the bisacrylamide/acrylamide ratio to $1 / 20$ increased the depth to $\approx 25$ and $\approx 20 \mu \mathrm{m}$, respectively (Supplementary Figure S1). Apparently, the lower percentage of acrylamide makes the PAA gel more compressible during centrifugation, whereas the higher percentage of the cross-linker reduces the rate of PAA swelling. The resulting 2-D arrangement allows all the cells within a 
microscopic field to be observed simultaneously (Figure 1C).

The merged gels can produce unordered 2-D cell arrays of a high density, which allows the cells to be screened at highthroughput using a manually operated microscope. Figure $2 \mathrm{~A}$ displays a fragment of a monolayer of $\approx 200,000$ HEK-293 cells transfected by a GFP-encoding plasmid and arrayed in a $14-\mathrm{mm}$-diameter gel. This corresponds to the surface density of $\approx 1300$ cells $/ \mathrm{mm}^{2}$. Figure $2 \mathrm{~B}$ shows that $\approx 40 \%$ of the cells seen in Figure 2A fluoresce. To estimate the screening throughput, we prepared a 2-D array of the same density upon a 10,000-fold dilution of the cells with nontransfected HEK-293 cells (Figure 2C). Eight GFP-producing cells were detected by eye in less than $30 \mathrm{~min}$ using a $40 \times$ objective, which corresponds to the screening speed of $>100$ cells/s. Although not as rapid as with an automated flow cytometer, the screening includes the option of image analysis, thereby increasing the reliability of detection and allowing cells to be distinguished from each other and from noncellular particles. Moreover, as each cell has a unique address in the array, the cells of interest can be subjected to a detailed analysis subsequent to the initial fast screening. The screening could be made faster and producing more information by using currently available automated instruments and software $(20,21)$.

The cells are firmly anchored in the gel matrix. Supplementary Figure S2 shows that neither the density nor the morphology of the immobilized cells appreciably changed during bathing the gel in a saline solution up to 3 days. This allows the cells in the array to be interrogated or synchronized (22) by merely adding an effector to the surrounding solution or changing the solution. It also enables long-lasting studies, including real-time or time-lapse observations of many individual cells in large populations, such as studies on intracellular dynamics (23). Importantly, cells become immobilized irrespective of their adhesive properties.

Incubation of the arrays in a complete growth medium resulted in cell growth and division (Figure 3 and Supplementary Figures S3-S5). Both the nonadherent cells (such as lymphoblasts; Supplementary Figure S3) and adherent cells (typical 2-D culture cells; Supplementary Figures S4 and S5) produced spheroid microcolonies characteristic of a 3-D culture. Unlike the on-top 3-D cultures (16-17), here cells are entirely embedded in the agarose matrix, which provides for secure immobilization of microcolonies during several days of culture. The PAA bed is chemically inert and presumably does not contact directly with the cells suspended in the agarose matrix. Yet, the PAA bed may mechanically influence the nearby cells, and this can be used to control the cell physiology through varying the PAA stiffness by changing the acrylamide and bisacrylamide concentrations (10).

Instead of agarose, other currently used 3-D matrices, both natural and synthetic (3-4,24-28), can be used to immobilize cells, or agarose can be supplemented with any desired component of ECM to better suit the requirements of a particular cell type (11,29-32). For example, the presence of bovine skin collagen (consisting of type I and type III collagens) in the agarose matrix promoted the growth of some adherent cells and influenced the colony morphology at the later stages (compare Supplementary Figure S5, A and B). Importantly, unlike the PAA-based on-top cultures (16), no covalent linkage of the collagen molecules to the PAA gel is needed here, as those molecules become mechanically entrapped within the agarose matrix (33).

Observation of growing GFP-producing HEK-293 cells with a confocal microscope (Figure 3B) revealed no lag in the colony formation, suggesting that the low temperature used for agarose gelling did not appreciably harm the cells. The doubling time was

\section{PARTICULAR ${ }^{\circledR}$ NANO-GOLD}

$\rightarrow$ FACILE STAINING, LABELING, TAGGING!

\section{gold nanoparticles for biotechnology:}

no photobleaching

brighter than dyes

visible in histology and

electron microscopy



advantages of our laser technology:

pure, ligand-free gold particles

without citrate or other residues

efficient conjugation to your

biomolecules in our labs
Particular customized material 
A
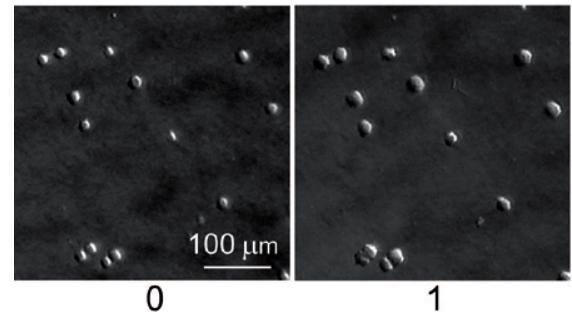

1

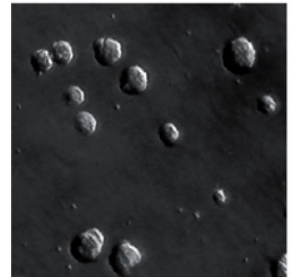

4

B

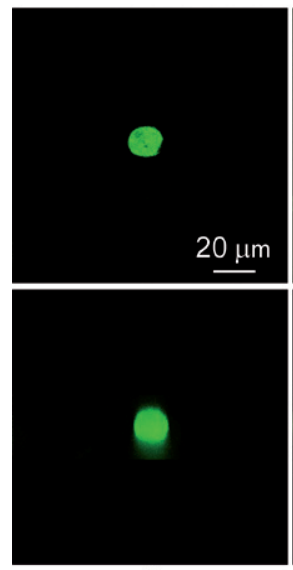

0

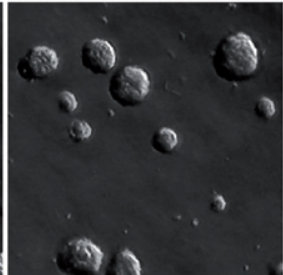

5

Incubation time, days

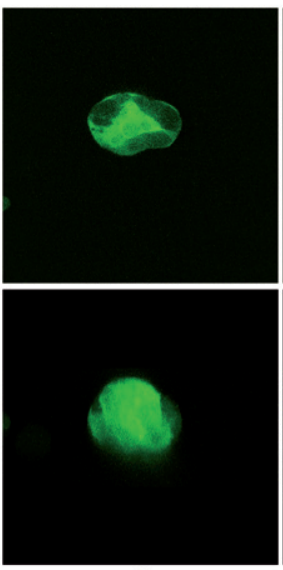

3

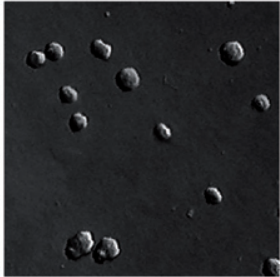

2

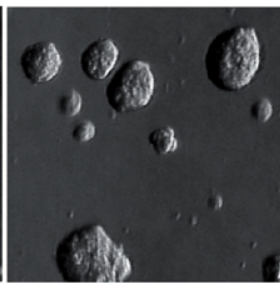

6
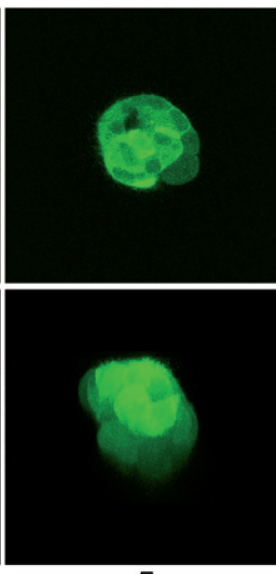

5

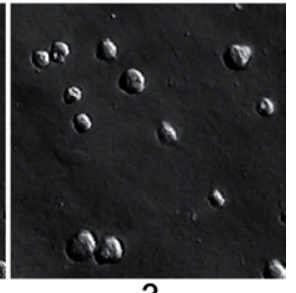

3

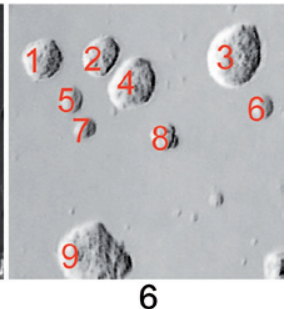

Incubation time, days

Figure 3. Time course of HEK-293 cell growth in merged gels containing complete growth medium. (A) Time-lapse inspection of an area of the cell monolayer with a bright-field microscope allows the origin of each microcolony in the area to be unambiguously traced. The grown colonies are numbered in the right-most panel of the bottom row, which is a negative of the 6-day image. (B) 3-D structure of typical microcolonies of GFP-producing cells at the specified time. Median optical sections of the colonies (top panels) and side views of the same microcolonies (bottom panels) obtained with a confocal microscope in the GFP fluorescence mode are shown.

$\approx 1$ day, the same as in the conventional 2-D culture, and after 7 days, a colony contained up to 200 cells. Colonies of this size were still retained by the agarose matrix. This allowed the contents of colonies to stay separate and allowed the cells from individual colonies to be accurately withdrawn for further use, in particular for isolating cell clones.

Importantly, our approach can also be used to generate stable cell lines by cloning. We started with a population of the HEK-293 cells transfected by a GFP-encoding plasmid that could not replicate inside the cells and contained no sequences promoting its integration into the chromosomes. Furthermore, we did not use antibiotic or any other form of chemical selection that could affect the cell physiology or result in cell line instability $(34,35)$ nor used a cell sorter to enrich the population by GFP-producing cells.

Approximately 30,000 transfected cells were arrayed at a density of $\approx 100$ cells $/ \mathrm{mm}^{2}$ (Figure 4A) in two PAA/agarose gels and allowed to grow for 7 days (Figure 4B). Then, fluorescing microcolonies that appeared homogenous (like those pinpointed with arrows in Figure 4B) were extracted from the agarose with a micromanipulatorhandled glass capillary. As a rule, a colony was pulled out as a whole, with no cells left behind. The extracted colonies were individ- ually transferred into wells of a standard 96-well plastic plate and incubated there for 7-10 days. Upon transfer, a colony flattened on the well bottom and continued to grow on the plastic surface as a 2-D culture. In the first experiment, whose results are presented in Figure 4, we picked 43 green colonies, 18 of which propagated ( $42 \%$ survival rate). [The survival rate was increased to $73 \%(66$ of 91) and 97\% (62 of 64) in the second and third experiments, respectively, owing to a more gentle manipulation of colonies at extraction.] Of those, we chose six variants by visual inspection, looking for fluorescence intensity, homogeneity, and growth rate; the latter was estimated as the time required for a colony to cover $\approx 20 \%$ of the well bottom.

All six cell lines (numbered 1 to 6 in Figure 4C) retained their phenotype after at least 30 passages. Thus, having started with the transfection of 30,000 cells, we obtained six stable cell lines after two rounds of selection in about 2 weeks. The first and most efficient round comprised the isolation of microcolonies that grew up, fluoresced, and were homogenous. This eliminated any cells that could not proliferate, or did not produce GFP, or produced mosaic colonies after a number of generations. In the second round, we verified the viability and homogeneity of the selected colonies. As the only purpose of this experiment was the demonstration of cell cloning, the clones were propagated and passaged in a conventional 2-D culture. Of course, if there was also a need to maintain the cell physiology, the merged gels described here could be used in the second round, too.

Here, colonies were selected by visual assessment of their homogeneity and fluorescence intensity, and manually picked. In a special experiment, the ability of this simple approach to yield high-quality cell preparations was confirmed by a flow cytometry analysis of the selected colonies (Supplementary Figure S6). Yet it is conceivable that the throughput and reliability of the procedure could be further improved by using automated devices for colony imaging and collection (36).

Cloning of eukaryotic cells is required in many basic and applied research areas (37-38), in particular for isolating cell lines stably producing the proteins of interest (39), but it still remains a challenging task. As pointed out by Clarke et al. (38) in regard to the existing cloning methods, "there is one problem common to them all: there is no way to be certain that the derived population originated from a single cell." The procedure reported here is essentially "cloning by micromanipulation," but it differs from 

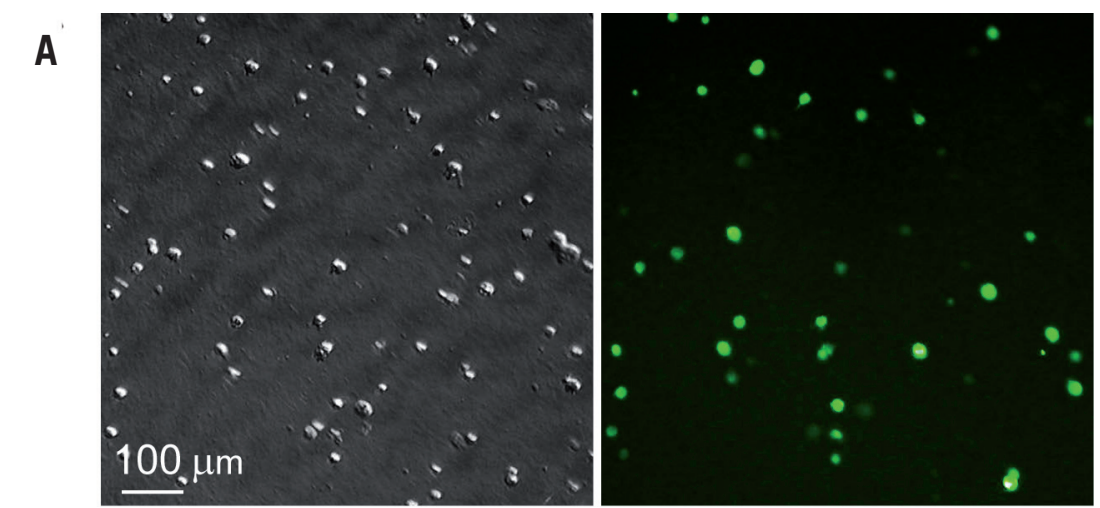

B
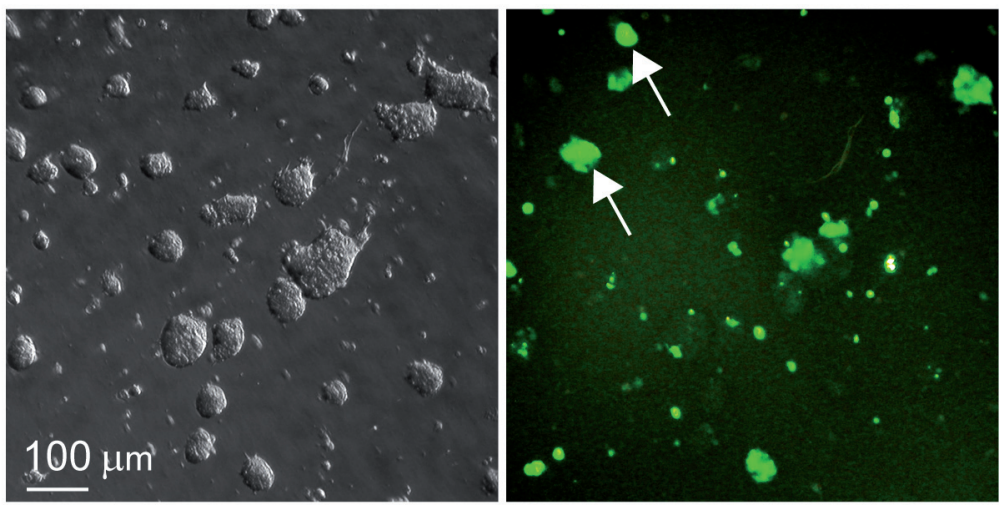

C
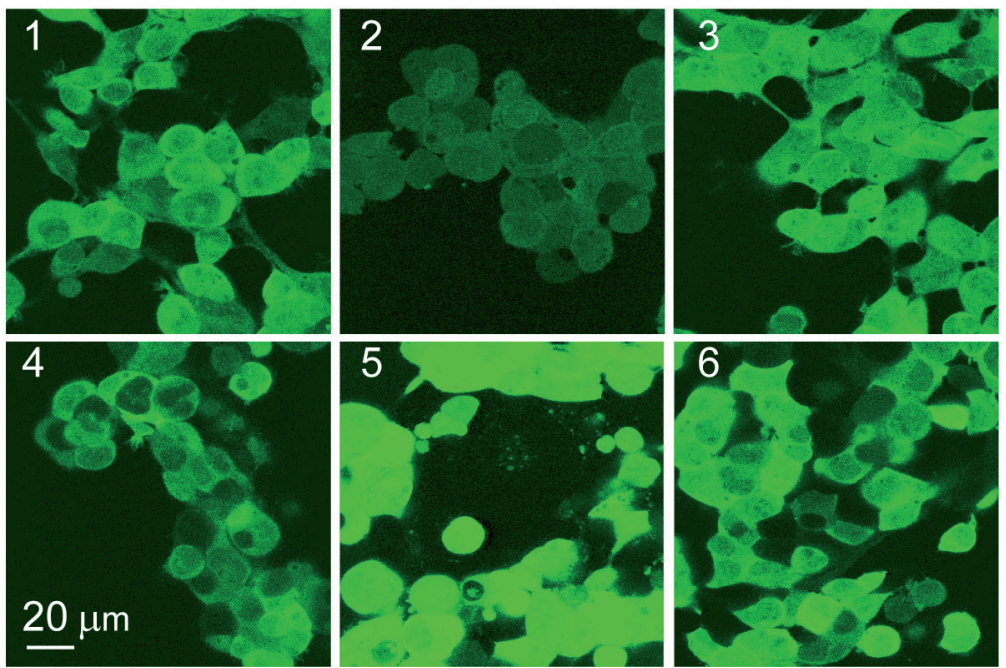

Figure 4. Isolation of GFP-producing cell lines from a population of HEK-293 cells transfected with a GFP-encoding plasmid. Bright field images (on the left) and GFP fluorescence (on the right) of cell monolayers after $18 \mathrm{~h}(\mathrm{~A})$ and 7 days (B) of incubation in a complete growth medium at $37^{\circ} \mathrm{C}$ and $5 \% \mathrm{CO}_{2}$. Arrows indicate typical colonies used for the isolation of cell clones. (C) Confocal microscope images of glass-adhered cells of six different lines stably producing GFP. All images were manipulated identically to allow the fluorescence intensities to be directly compared.

the earlier published protocol (38) in that the cells are presented as a monolayer and immobilized in a gel, rather than provided as a suspension in which cells can freely migrate at different depths. Hence, the potential problems of cloning by micromanipulation (limited depth of microscopy field and eventual adherence of cells to the outside of the micropipet; see Reference 38) can be overcome. Moreover, by enabling monitoring the entire process of the formation of individual colonies, the present method allows the colonies that have originated from single cells to be precisely identified. This feature is illustrated in Figure 3A; it can be seen that colonies numbered 2 to 8 have each originated from a single cell, while colonies 1 and 9 have originated from two and four cells, respectively. Therefore, we believe

\section{Biosciences, Inc.}

\section{D Cell Culture In Hours Not Days}

The Bio-Assembler ${ }^{\mathrm{TM}}$ from Nano3D

Biosciences is a fast and easy 3D system for creating an in vivo culture microenvironment.

Cells will levitate and self-assemble near the air-media interface. In hours not days you'll see clear formation of accurate 3D structures and cell-cell interactions.

- Fast - 3D structures in hours not days

- Easy - similar to 2D culture

- Accurate - in vivo-like results with in vitro techniques

Start

$<24$ Hours
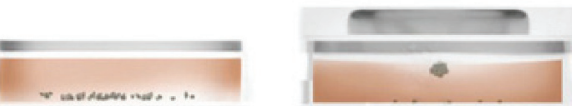

Dispersed Cells

3D Multicellular Structure

\section{Check Out Our Data}

Co-culture and post-culture manipulation becomes effortless. No bioreactors, gels, or deleterious effects. Extensive testing demonstrates remarkable in vivo resemblance.

See for yourself and order today at www.n3DBio.com

Souza, G. et al. Nature Nanotechnology 5 , 291-296 (2010).

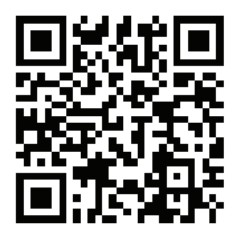


that the approach described here enables, at least potentially, the true cloning of eukaryotic cells.

In conclusion, it should be noted that the method reported here enables cloning from rather dense cell populations. In the experiment described in Figure 4, the cells were immobilized at a surface density of $\approx 100$ cells $/ \mathrm{mm}^{2}$, which, assuming that the layer thickness was $10 \mu \mathrm{m}$ (compare Figure 1B), corresponded to the volume concentration of $10^{7}$ cells $/ \mathrm{mL}$. Although still lower than the cell concentration in solid tissues of up to $10^{9}$ cells $/ \mathrm{mL}$ (38), it equals the concentration of leukocytes in the peripheral blood, with the same mean cell-to-cell distances. This largely overcomes the negative effects of the very low population density at which cells occur during the conventional cloning procedures (38).

\section{Acknowledgments}

The authors thank Drs. F.K. Gioeva and T.R. Samatov for their help and advice, I.A. Eliseeva for assistance in the acquisition of confocal images, and N.A. Nikitenko for carrying out flow cytometer analyses. This work was supported in part by program "Molecular and Cell Biology" of the Russian Academy of Sciences and by the Russian Foundation for Basic Research.

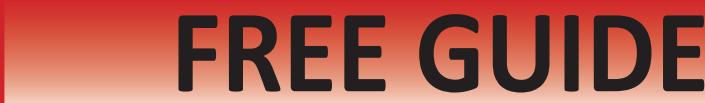

\section{Homogenization/Disruption} * of Biological Samples
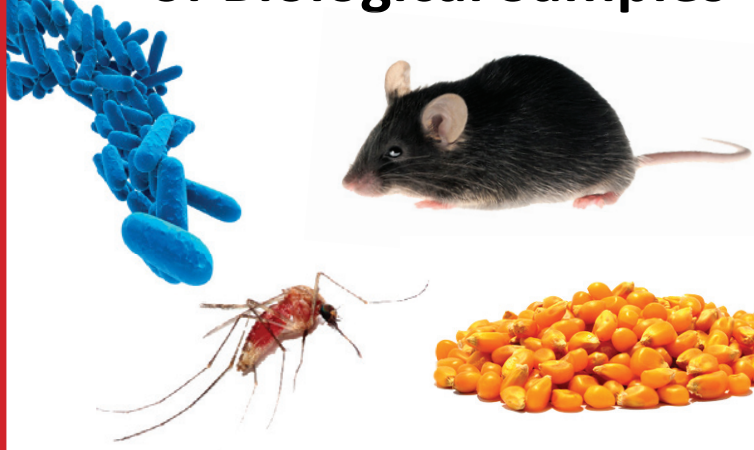

Protocols and Strategies Including: Chemical/Enzymatic Methods Shearing \& Grinding Options High Throughput Strategies

For a free download visit us at: www.opsdiagnostics.com OPS DIAGNOSTICS, LLC 908.253 .3444

\section{Competing interests}

A.B.C. and H.V.C. are co-inventors and co-owners of a patent (no. RU2394915) and patent applications (nos. WO2007111639, US2009105082, and EP1999268) disclosing the method of merged gels. A.A.G. declares no competing interests.

\section{References}

1. Bissell, M.J., A. Rizki, and I.S. Mian. 2003. Tissue architecture: the ultimate regulator of breast epithelial function. Curr. Opin. Cell Biol. 15:753-762.

2. Zhang, S. 2004. Beyond the Petri dish. Nat. Biotechnol. 22:151-152.

3. Griffith, L.G. and M.A. Swartz. 2006. Capturing complex 3D tissue physiology in vitro. Nat. Rev. Mol. Cell Biol. 7:211-224.

4. Tibbitt, M.W. and K.S. Anseth. 2009. Hydrogels as extracellular matrix mimics for 3D cell culture. Biotechnol. Bioeng. 103:655-663.

5. Roskelley, C.D., P.Y. Desprez, and M.J. Bissell. 1994. Extracellular matrixdependent tissue-specific gene expression in mammary epithelial cells requires both physical and biochemical signal transduction. Proc. Natl. Acad. Sci. USA 91:12378-12382.

6. Weaver, V.M., O.W. Petersen, F. Wang, C.A. Larabell, P. Briand, C. Damsky, and M.J. Bissell. 1997. Reversion of the malignant phenotype of human breast cells in three-dimensional culture and in vivo by integrin blocking antibodies. J. Cell Biol. 137:231-245.

7. Pampaloni, F., E.G. Reynaud, and E.H. Stelzer. 2007. The third dimension bridges the gap between cell culture and live tissue. Nat. Rev. Mol. Cell Biol. 8:839-845.

8. Yamada, K.M. and E. Cukierman. 2007. Modeling tissue morphogenesis and cancer in 3D. Cell 130:601-610.

9. Bissel, M.J., D.C. Radisky, A. Rizki, V.M. Weaver, and O.W. Petersen. 2002. The organizing principle: microevironmental influences in the normal and malignant breast. Differentiation 70:537-546.

10. Engler, A.J., S. Sen, H.L. Sweeney, and D.E. Discher. 2006. Matrix elasticity directs stem cell lineage specification. Cell 126:677-689.

11. Sabeh, F., R. Shimizu-Hirota, and S.J. Weiss. 2009. Protease-dependent versus -independent cancer cell invasion programs: three-dimensional amoeboid movement revisited. J. Cell Biol. 185:11-19.

12. Zegers, M.M.P., L. O’Brien, W. Yu, A. Datta, and K.E. Mostov. 2003 Epithelial polarity and tubulogenesis in vitro. Trends Cell Biol. 13:169173.

13. Buxboim, A., I.L. Ivanovska, and D.E. Discher. 2010. Matrix elasticity, cytoskeletal forces and physics of the nucleus: how deeply do cells 'feel' outside and in? J. Cell Sci. 123:297-308.

14. Pampaloni, F., E.H. Stelzer, and A. Masotti. 2009. Three-dimensional tissue models for drug discovery and toxicology. Recent Pat. on Biotechnol. 3:103-117.

15. Pampaloni, F. and E. Stelzer. 2009. Three-dimensional cell cultures in toxicology. Biotechnol. Genet. Eng. Rev. 26:117-138.

16. Wang, Y.L. and R.J. Pelham, Jr. 1998. Preparation of a flexible, porous polyacrylamide substrate for mechanical studies of cultured cells. Methods Enzymol. 298:489-496.

17. Lee, G.Y., P.A. Kenny, E.H. Lee, and M.J. Bissell. 2007. Three-dimensional culture models of normal and malignant breast epithelial cells. Nat. Methods 4:359-365.

18. Gordeev, A.A., T.R. Samatov, H.V. Chetverina, and A.B. Chetverin. 2011. $2 \mathrm{D}$ format for screening bacterial cells at the throughput of flow cytometry. Biotechnol. Bioeng. 108:2682-2690.

19. Chetverin, A.B., T.R. Samatov, and H.V. Chetverina. 2007. Non-invasive molecular colony methods, kits and apparatus. PCT Publication WO2007111639.

20. Henriksen, M. 2010. Quantitative imaging cytometry: instrumentation of choice for automated cellular and tissue analysis. Nat. Methods 7:i-ii.

21. Conrad, C., A. Wünsche, T.H. Tan, J. Bulkescher, F. Sieckmann, F. Verissimo, A. Edelstein, T. Walter, et al. 2011. Micropilot: automation of fluorescence microscopy-based imaging for systems biology. Nat. Methods 8:246-249.

22. Adams, R.L.P. 1990. Cell Culture for Biochemists, 2nd ed. Elsevier, Amsterdam, The Netherlands.

23. Eden, E., N. Geva-Zatorsky, I. Issaeva, A. Cohen, E. Dekel, T. Danon, L. Cohen, A. Mayo, and U. Alon. 2011. Proteome half-life dynamics in living human cells. Science 331:764-768.

24. Cukierman, E., R. Pankov, D.R. Stevens, and K.M. Yamada. 2001. Taking cell-matrix adhesions to the third dimension. Science 294:1708-1712. 
25. Zhang, S., F. Gelain, and X. Zhao. 2005. Designer self-assembling peptide nanofiber scaffolds for 3D tissue cell cultures. Semin. Cancer Biol. 15:413420 .

26. Shapira-Schweitzer, K., M. Habib, L. Gepstein, and D. Seliktar. 2009. A photopolymerizable hydrogel for 3-D culture of human embryonic stem cell-derived cardiomyocytes and rat neonatal cardiac cells. J. Mol. Cell. Cardiol. 46:213-224.

27. Kraehenbuehl, T.P., R. Langer, and L.S. Ferreira. 2011. Three-dimensional biomaterials for the study of human pluripotent stem cells. Nat. Methods 8:731-736.

28. Gaggioli, C., S. Hooper, C. Hidalgo-Carcedo, R. Grosse, J.F. Marshall, K. Harrington, and E. Sahai. 2007. Fibroblast-led collective invasion of carcinoma cells with differing roles for RhoGTPases in leading and following cells. Nat. Cell Biol. 9:1392-1400.

29. Serebriiskii, I., R. Castelló-Cros, A. Lamb, E.A. Golemis, and E. Cukierman. 2008. Fibroblast-derived 3D matrix differentially regulates the growth and drug-responsiveness of human cancer cells. Matrix Biol. 27:573-585.

30. Amjad, S.B., R. Carachi, and M. Edward. 2007. Keratinocyte regulation of TGF- $\beta$ and connective tissue grow th factor expression: a role in suppression of scar tissue formation. Wound Repair Regen. 15:748-755.

31. Katz, E., S. Dubois-Marshall, A.H. Sims, D. Faratian, J. Li, E.S. Smith, J.A. Quinn, M. Edward, et al. 2010. A gene on the HER2 amplicon, C35, is an oncogene in breast cancer whose actions are prevented by inhibition of Syk. Br. J. Cancer 103:401-410.

32. Katz, E., S. Dubois-Marshall, A.H. Sims, P. Gautier, H. Caldwell, R.R. Meehan, and D.J. Harrison. 2011. An in vitro model that recapitulates the epithelial to mesenchymal transition (EMT) in human breast cancer. PLoS One 6:e17083.

33. Ulrich, T.A., A. Jain, K. Tanner, J.L. MacKay, and S. Kumar. 2010. Probing cellular mechanobiology in three-dimensional culture with collagenagarose matrices. Biomaterials 31:1875-1884.

34. Kaufman, W.L., I. Kocman, V. Agrawal, H.P. Rahn, D. Besser, and M. Gossen. 2008. Homogeneity and persistence of transgene expression by omitting antibiotic selection in cell line isolation. Nucleic Acids Res. 36:e111.

35. Schiedner, G., S. Hertel, C. Bialek, H. Kewes, G. Waschütza, and C. Volpers. 2008. Efficient and reproducible generation of high-expressing, stable human cell lines without need for antibiotic selection. BMC Biotechnol. 8:13.

36. Haupt, S., J. Grützner, B.H. Rath, H. Möhlig, and O. Brüstle. 2009. Automated selection and collection of pluripotent stem cell colonies using the CellCelector. Nat. Methods 6:iii-iv.

37. Barnes, L. 2007. Stability: establishing clones, genetic monitoring and biological performance, p. 113-124. In G. Stacey and J. Davis (Eds), Medicines from Animal Cell Culture. John Wiley \& Sons, Chichester, UK.

38. Clarke, J., A.J. Porter, and J.M. Davis. 2011. Cloning, p. 231-254. In J.M. Davis (Ed.), Animal Cell Culture: Essential Methods. John Wiley \& Sons, Chichester, UK.

39. Wurm, F.M. 2004. Production of recombinant protein therapeutics in cultivated mammalian cells. Nat. Biotechnol. 22:1393-1398.

Received 18 September 2011; accepted 4 April 2012.

Address correspondence to Alexander B. Chetverin, Institute of Protein Research of the Russian Academy of Sciences, 4 Institutskaya Street, Pushchino, Moscow Region, Russia.Email: alexch@vega.protres.ru

Topurchase reprints of this article,contact: biotechniques@fosterprinting.com

\section{Prove \& Publish}

\section{Cell Line Authentication}

- STR Analysis of Human DNA

- Contamination Detection

- Species Determination

- Mycoplasma

- High Volume Laboratory

- Results in 5 Days

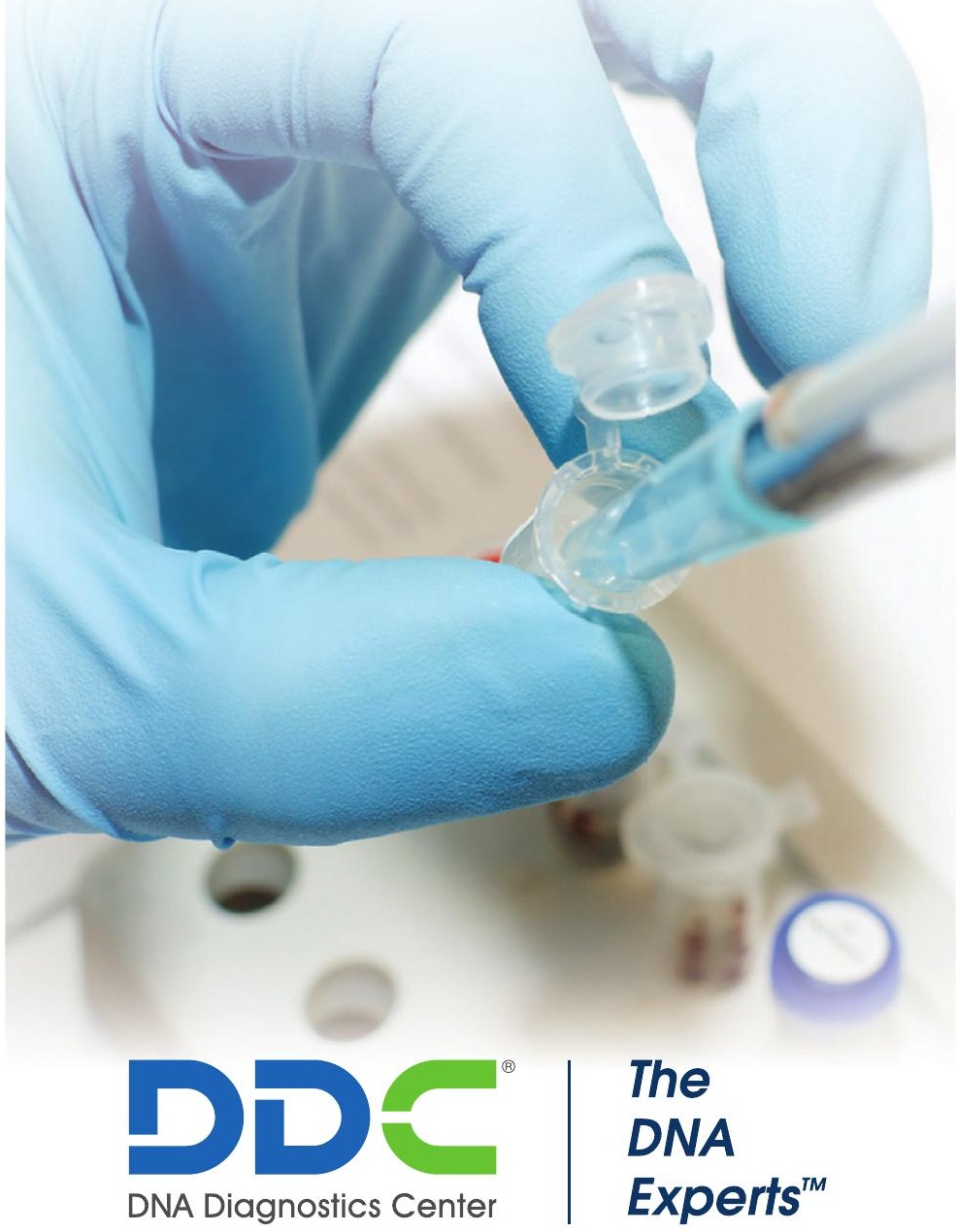

www.DNAcenter.com/cell-line
1-800-831-9830 